\title{
Ensino superior brasileiro e sua influência no desenvolvimento regional
}

\author{
Brazilian higher education and its influence on regional development \\ La educación superior brasileña y su influencia en el desarrollo regional
}

Recebido: 26/07/2021 | Revisado: 31/07/2021 | Aceito: 03/08/2021 | Publicado: 08/08/2021

Amanda Beatriz Albernaz de Araújo
ORCID: https://orcid.org/0000-0002-0376-6402
Pontifícia Universidade Católica de Goiás, Brasil
E-mail: engenheira.albernaz@gmail.com
Antonio Pasqualetto
ORCID: https://orcid.org/0000-0002-8639-6725
Pontifícia Universidade Católica de Goiás, Brasil
Instituto Federal de Educação, Ciência e Tecnologia de Goiás, Brasil
E-mail: profpasqualetto@gmail.com
Pedro Araújo Pietrafesa
ORCID: https://orcid.org/0000-0003-0542-4753
Pontifícia Universidade Católica de Goiás, Brasil
E-mail: pedro.pietrafesa @gmail.com
Ilana Marques de Jesus Beltrão
ORCID: https://orcid.org/0000-0003-3582-0116
Pontifícia Universidade Católica de Goiás, Brasil
E-mail: ibeltro@gmai.com

\section{Resumo}

Todos os países que se desenvolveram no mundo, colocaram a educação como uma de suas prioridades. Neste sentido, objetivou-se avaliar a expansão do ensino superior no Brasil e suas contribuições ao desenvolvimento regional. A metodologia exploratória bibliográfica do tipo qualitativa e constitui de consulta aos órgãos oficiais do governo e literatura sobre o tema, desde as primeiras instituições de ensino superior em 1808 até 2020, resgatando marcos históricos e políticas públicas voltadas à educação superior, além de estudos em artigos, teses de dissertação em bancos de dados como Scopus e Scielo. Os resultados demonstram expansão e interiorização, ampliando o acesso, bem como sendo fator de ativação da economia local. Entretanto, a taxa bruta de matrículas no ensino superior e a taxa líquida de escolarização ainda estão aquém das metas estabelecidas no Programa Nacional de Educação, demandando novos avanços necessitando de melhorias para que se alcance o proposto ao longo dos anos.

Palavras-chave: Educação; Políticas públicas; Economia.

\begin{abstract}
All countries that have developed in the world have placed education as one of their priorities. In this sense, the objective was to evaluate the expansion of higher education in Brazil and its contributions to regional development. The bibliographical exploratory methodology of the qualitative type and constitutes consultation with official government agencies and literature on the subject, from the first higher education institutions in 1808 to 2020 , recovering historical landmarks and public policies aimed at higher education, as well as studies in articles , dissertation theses in databases such as Scopus and Scielo. The results demonstrate expansion and internalization, expanding access, as well as being a factor in activating the local economy. However, the gross enrollment rate in higher education and the net enrollment rate still fall short of the goals established in the National Education Program, demanding new advances that need improvements to achieve what was proposed over the years.
\end{abstract}

Keywords: Education; Public policy; Economy.

\section{Resumen}

Todos los países que se han desarrollado en el mundo han colocado la educación como una de sus prioridades. En este sentido, el objetivo fue evaluar la expansión de la educación superior en Brasil y sus contribuciones al desarrollo regional. La metodología exploratoria bibliográfica de tipo cualitativo y constituye la consulta con organismos gubernamentales oficiales y literatura sobre el tema, desde las primeras instituciones de educación superior en 1808 hasta 2020, recuperando hitos históricos y políticas públicas orientadas a la educación superior, así como estudios en artículos, tesis de disertación en bases de datos como Scopus y Scielo. Los resultados demuestran expansión e internalización, ampliando el acceso, además de ser un factor activador de la economía local. Sin embargo, la tasa bruta de matrícula en la educación superior y la tasa neta de matrícula aún están por debajo de las metas establecidas en el Programa Nacional de Educación, exigiendo nuevos avances que necesitan mejoras para lograr lo propuesto a lo largo de los años.

Palabras clave: Educación; Políticas públicas; Economía. 


\section{Introdução}

A educação é um elemento importante de qualquer sociedade. Nela são depositados valores de formação de cidadania e conceitos que possibilitam a construção de uma nação.

A educação superior é como um passaporte do ensino. As universidades contribuem para o bem público, cidades e regiões ao qual estão inseridas, cooperam com geração de empregos na instituição e até mesmo no mercado local que necessita de maior produção, desenvolvimento cultural com promoção de eventos, inovação e pesquisa geralmente em parceria com empresas locais, além de projetos de extensão que visam proporcionar atividades voltadas ao bem estar social.

Serra et al. (2020) colocam essas instituições como agentes de desenvolvimento econômico, social e urbano, e por serem elementos tão importantes na sociedade, são alvos de políticas públicas.

Apesar dos avanços obtidos nestes séculos, há pessoas desprovidas de Universidade, que embora desejada por muitos, possibilitada a poucos, dada a disponibilidade de vagas, distância, mensalidades, dentre outros fatores.

Portanto, programas que possibilitam a democratização e interiorização são fundamentais. É nesse contexto do acesso ao ensino superior que se faz necessário a implantação de políticas públicas, que aqui são tratadas como sistemas de ações para produzir efeitos específicos, nesse caso de ampliação do Ensino Superior.

Nesse sentido, objetivou-se avaliar a evolução de políticas públicas e programas voltados à educação superior no Brasil, como PROUNI, SISU, FIES e REUNI, e como podem contribuir com o desenvolvimento regional brasileiro e também no local onde são implementadas.

\section{Metodologia}

A pesquisa é do tipo exploratória, bibliográfica, constituída por levantamento de referências, que em tese aprimora ideias ou pode contribuir para descoberta de intuições a fim de desenvolver pesquisas para comprová-las.

A abordagem é qualitativa que segundo Silveira e Córdova (2009, p.31), "busca explicar o porquê das coisas, exprimindo o que convém ser feito, mas não quantificam os valores e as trocas simbólicas nem se submetem à prova de fatos".

Se embasa em documentos oficiais publicados por órgãos, como por exemplo do Ministério da Educação e Instituto Brasileiro de Geografia e Estatística, para compreender a relação de políticas públicas e a expansão do ensino superior, elucidando relações entre as Instituições e o desenvolvimento Regional

O estudo ocorreu em 2020 e 2021 em distintos momentos evolutivos, separados por marcos históricos do processo de expansão do Ensino Superior, fazendo a cronologia e comparando com dados de acesso à educação para identificar se essas políticas ampliaram o acesso às Instituições de Ensino Superior (IES), com destaque aos Programa Universidade para todos (PROUNI), Reestruturação e Expansão das Universidades Federais (REUNI), Sistema de Seleção Unificada (SISU) e Financiamento Estudantil (FIES).

Um paralelo entre os anos 2000 com a atual realidade de 2020 comparando dados de número de matrículas e número de IES juntamente à análise dos programas verificando se ocorreu ampliação do ensino superior, e como essas ações influenciam no desenvolvimento regional.

Inicialmente, no tópico dois, foi definido políticas públicas e como elas se relacionam com o ensino superior e consequentemente com o desenvolvimento regional, no tópico três foi elaborado a cronologia de marcos importantes na educação superior, em seguida o tópico quatro foi construído com o levantamento de políticas públicas e programas de expansão do ensino superior. Por fim, no tópico cinco faz-se a relação entre a interiorização do ensino superior e o desenvolvimento regional, antes de trazer as considerações finais. 


\section{Políticas Públicas de Educação e Desenvolvimento Regional}

Políticas públicas podem ser definidas como uma ação do Estado em prol de uma finalidade específica, seja solução de problemas ou prevenção. De forma mais ampla, podem ser definidas como a materialização da intervenção do Estado, porém, podem também abarcar políticas de organizações privadas ou não governamentais, principalmente em casos de diversificação de fontes e recursos, mas sempre com caráter público, pois afetam e comprometem toda a sociedade. (Viegas et al., 2020).

Quando são voltadas à educação podem ser por meio de programas educacionais, leis, planejamentos, investimentos que resultem na criação, ampliação ou melhoria dentro desse setor. Vale ressaltar que as políticas não se resumem apenas a programas pois esses são "atividades específicas nas quais as agências se envolvem durante a implementação de uma política pública.”. (Viegas et al., 2020, p.43420)

Dentro do contexto de políticas para o Ensino Superior o eixo central é o Plano Nacional de Educação (PNE), que desde 2014 estabelece diretrizes norteadoras para a educação com limite o ano de 2024, e como marcos legais para sua implantação tem-se a Constituição Federal de 1988 com o descrito: "Na organização de seus sistemas de ensino, a União, os Estados, o Distrito Federal e os Municípios definirão formas de colaboração, de modo a assegurar a universalização do ensino obrigatório.”, e a Lei de Diretrizes e Bases da Educação Nacional (LDB), Lei no 9.394 de 1996 com o trecho: “A União, os Estados, o Distrito Federal e os Municípios organizarão, em regime de colaboração, os respectivos sistemas de ensino" (Plano nacional de educação em movimento, 2014). Em sua meta de número 12, das vinte elaboradas, estabelece o seguinte para a expansão do Ensino Superior no Brasil: Elevar a taxa bruta de matrícula na educação superior para 50\% (cinquenta por cento) e a taxa líquida para $33 \%$ (trinta e três por cento) da população de 18 (dezoito) a 24 (vinte e quatro) anos, assegurada a qualidade da oferta e expansão para, pelo menos, $40 \%$ (quarenta por cento) das novas matrículas, no segmento público. (Plano nacional de educação, 2014, p.13)

Para fazer a interação entre políticas públicas do ensino Superior com desenvolvimento é necessário entender a diferenciação entre regional e local para que se entenda em que dimensão será tratada o impacto das IES. Principal diferença pode ser por um recorte espacial, a escala regional tem maior abrangência que a local, e é menos restrito.

(...) no contexto do desenvolvimento regional entende-se a região como parte de uma totalidade, totalidade não mais orgânica ou lógica, nem uma totalidade harmônica e sim uma totalidade histórica, entendida à luz da concepção de Formação Econômico-Social. (Etges \& Degrandi, 2013, p. 90)

Já desenvolvimento deve ser pautado em melhorias da tripla condição; social, econômica e cultural, ou seja, deve ocasionar bem estar social com qualidade de vida onde a renda seja accessível à população. Ainda pode-se pensar nesse desenvolvimento como explicado por Dallabrida (2010, p.169) "como um processo de mudança estrutural empreendido por uma sociedade organizada territorialmente"

Em seu estudo, Theis (2019) identifica bibliografias que demonstram que Desenvolvimento pode atribuir a seguinte definição:

[...] desenvolvimento não se limita a prover uma dada população de bens materiais e econômicos. Pelo contrário, é preciso considerar o seu caráter de totalidade, de um todo indissociável, assim permitindo que o conceito inclua preocupações como: a redução de desigualdades territoriais, a promoção de justiça social e espacial, e a busca da dignidade como sua finalidade última. (Theis, 2019, p. 338)

Perante essa diferenciação, pode ser entendido como desenvolvimento regional a melhoria de índices como: crescimento econômico, fatores sociais, culturais, ambientais e políticos. São ações em conjunto com o público e o privado que 
visam levar soluções aos problemas de determinada região. É nesse contexto de oportunidades, que se inserem os impactos gerados por universidades.

A importância da Educação Superior se destaca como elemento para estimular as capacidades de desenvolvimento da região, melhorando as competências de recursos humanos e impulsionando atividades criativas e inovadoras. Nessa direção, as IES potencializam os níveis de qualificação e qualidade na capacitação das pessoas.

Guedes e Santos (2019) defendem que as universidades ainda podem contribuir com inovação junto às empresas, que fazem alianças para criar conhecimentos sofisticados, além de desenvolver e disseminar tecnologias diferenciadas. Afirmam ainda, que essa interação é benéfica para empresas, universidades e para a região inserida, afinal, permite o compartilhamento de "conhecimentos, pessoas e tecnologias". (Guedes \& Santos, 2019, p.345).

Castells (2003) coloca as universidades como fator de criação das cidades, pois, são essenciais na dinamização do tecido urbano, produz mão de obra qualificada, indivíduos inovadores e ideias novas. Impactos que vão além do aumento em indicadores econômicos, essas alterações podem afetar o desenvolvimento de toda a região.

Assim, pode-se verificar, que como afirmado por Silva, Lopes e Júnior (2009), as políticas públicas podem atender a questões multidirecionais, onde uma ação com foco na educação, por exemplo, pode afetar questões econômicas e sociais do seu entorno.

\section{Marcos Históricos do Processo de Expansão do Ensino Superior}

Quando se trata do ensino superior no Brasil há necessidade de incursão na história de sua implantação e expansão. E isso é de suma importância para que se possa fazer a ligação dos fatos.

A história começou de forma tardia quando comparada com países da América Latina, que tiveram como colonizadores a Espanha, enquanto esse espalhava universidades por suas colônias, Portugal fazia-se limitado às Universidades das Metrópoles: Coimbra e Évora.

O modelo mais próximo de Instituição de Ensino Superior chegou por aqui somente a partir dos anos de 1808, como ilustrado na figura 1, com a criação do curso de Cirurgia, Anatomia e obstetrícia na cidade do Rio de Janeiro (atual Faculdade de Medicina da Universidade Federal do Rio de Janeiro) e também em Salvador (atual Faculdade de Medicina da Universidade Federal da Bahia). Ainda não existiam instituições que tivessem diversos cursos superiores, apenas cursos isolados (Villalta, 1997).

A Figura 1 traz uma cronologia, para melhor entendimento desse contexto histórico de marcos importantes a serem analisados nessa pesquisa, no que diz respeito à evolução dos programas de políticas públicas voltadas ao Ensino Superior.

Somente no ano de 1920 foi a consolidação da confederação de escolas, sendo a Universidade do Rio de Janeiro a primeira. Sete anos mais tarde, em 1927, foi inaugurada a Universidade Federal de Minas Gerais, às quais ficaram configuradas como modelos napoleônicas, concebidas para formação ao mercado de trabalho, sem foco em pesquisas. Em 1934 foi criada a Universidade de São Paulo, e a partir dos anos de 1950 houve expansão das Instituições Superiores Federais no Brasil. (Aprile \& Barone, 2009). 
Figura 1 - Cronologia de fatos históricos da educação superior no Brasil.

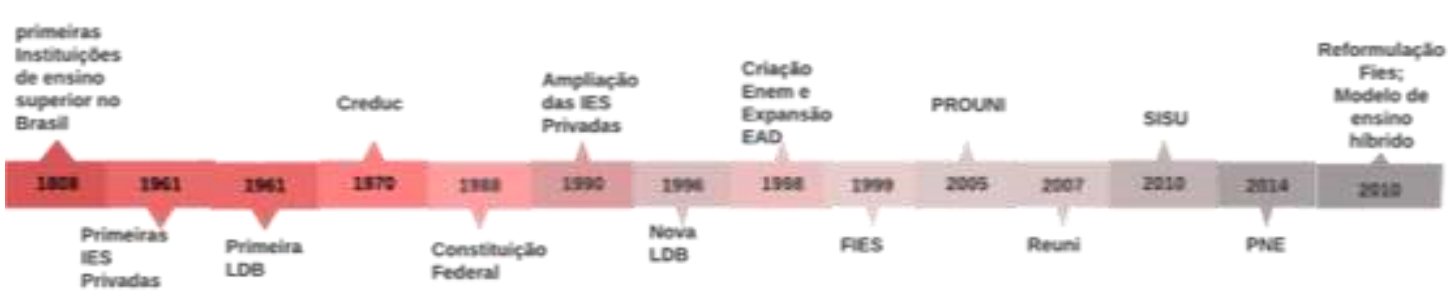

Fonte: Autores (2020).

A existência destas instituições não necessariamente representava acesso a todos que desejavam, eram destinadas principalmente pessoas de maior classe social e aos líderes religiosos. O maior acesso às instituições se inicia pela reforma universitária, que data do início dos anos de 1960, como resultado do esforço de um movimento estudantil. (Mendonça, 2000).

Segundo Mendonça (2000) em 1962 foi inaugurada a Universidade de Brasília (UNB), que trazia consigo um novo modelo que associava o ensino e a pesquisa, rompendo com o até então praticado no país. Porém, em 1968 o governo militar coloca em voga a reforma universitária, por meio da lei $\mathrm{n}^{\circ} 5540$, onde as universidades teriam caráter de formação profissional, focado apenas no mercado de trabalho e a pesquisa então ficaria para o âmbito da pós-graduação (Mendonça, 2000).

Vieira (1991) fez uma avaliação dos vinte anos que se seguiram a lei $n^{\circ} 5540$ e chegou à conclusão de que houve a solidificação da pós graduação voltada para carreira de docência nas universidades federais, que estariam tratando de pesquisa e extensão, enquanto as IES privadas (que datam suas primeiras instalações a partir de 1891, visto na figura 1) cresciam e recebiam incentivos para sua expansão, principalmente nos anos 1990, e essas se voltariam principalmente para formação de profissionais para o mercado de trabalho.

A expansão das IES privadas (Quadro 1) se materializou em quantidade nos anos 2000, de um total de 1180 instituições apenas 176 eram públicas, de acordo à pesquisa realizada pelo Instituto Nacional de Estudos e Pesquisas Educacionais Anísio Teixeira.

Quadro 1. Número de matrículas por natureza administrativa no ensino superior do Brasil.

\begin{tabular}{|c|c|c|c|c|}
\hline \multicolumn{2}{|c|}{ Matrículas } \\
\hline 1990 & Públicas & Crescimento \% & Privadas & Crescimento \% \\
\hline 2000 & 578.625 & - & 961455 & - \\
\hline 2010 & 1.461 .696 & 53 & 1807219 & 88 \\
\hline 2018 & 2.077 .481 & 65 & 3987424 & 60 \\
\hline
\end{tabular}

Fonte: Elaboração própria com dados do censo da educação superior. (Inep, 2019).

Sguissardi (2008), em sua pesquisa, constatou que de 2000 a 2010 o número de matrículas nas IES privadas cresceu numa escala de $121 \%$, enquanto as públicas ficaram na faixa de $65 \%$, onde a quantidade de matrícula nas IES privadas esteve à frente em todos os anos.

Porém, antes de explanar sobre os programas e políticas, é necessário que se entenda a diferença entre ampliação e democratização do acesso ao Ensino Superior. O primeiro se refere à criação de novas vagas nas Instituições (tanto em públicas quanto particulares), e será tratado com maior ênfase nessa pesquisa. O segundo, a democratização possui um sentido diferente, pois esse necessita maior oferta de vagas, mas requer que seja de fácil acesso as camadas dos não privilegiados e precisa analisar se os estudantes conseguem se manter até a formação. 


\section{Programas de Expansão do Ensino Superior no Brasil}

Após os anos 1990, a discussão sobre a necessidade de medidas que viabilizassem o acesso de jovens das camadas mais populares ao ensino superior se mostra cada vez mais importante. É quando esse assunto se insere no quadro de políticas públicas da educação.

Aprile e Barone (2009) expõem que, ainda nos anos 90, foram elaborados vínculos quase que lineares entre a entrada e permanência de um indivíduo em seu emprego com o grau de escolaridade do mesmo, afinal, o mercado buscava competitividade, capacidade e maior produção, ficou ainda mais incisivo a necessidade do poder público interferir para proporcionar avanço no setor.

No período de 1994 a 2002 houve avanço no ensino privado, com facilitação ao processo de reconhecimento, autorização e credenciamento de novas instituições, além do ajuste fiscal, que já existia desde os anos 1990 (Durhan, 2010).

Mesmo com ampliação do número das IES privadas, surgem complicações decorrentes do alto índice de inadimplência, e as inúmeras vagas ofertadas não conseguiam o público necessário. A simples expansão não era suficiente, se a maior parte da população não conseguia entrar e se manter no ensino superior, o que mostra a necessidade de interferência do Estado para maior igualdade na educação, ou seja, havia expansão, mas não democratização.

Durante os anos de 1990, o Banco Mundial (BM) promoveu políticas de interferência na Educação Superior, e Lima (2011) defende que, aqui no Brasil, os dois eixos guias para as reformulações do ensino eram: maior diversidade de IES e de cursos, além de maiores fontes de financiamento estudantil, para que as vagas do setor privado não ficassem ociosas. Daí surgiu a maior necessidade de programas de políticas públicas que pudessem viabilizar a entrada e permanência dos estudantes no Ensino Superior.

\subsection{Programa de Crédito Estudantil (PCE/CREDUC)}

O Programa de Crédito Estudantil (PCE/CREDUC) foi criado em 1970 e se caracterizava como financiamento estudantil. Entretanto, com o passar do tempo, os alunos que iam concluindo os estudos não pagavam as dívidas do financiamento, culminando numa alta inadimplência, e em 1983 já estava praticamente falido. Foram feitas reformulações na tentativa de melhorar o sistema, como por exemplo: novas fontes de investimento e alteração do período de carência, a fim de trazer novamente a eficácia do programa.

Em 1992, através da Lei 8.436, o programa foi institucionalizado sendo administrado e supervisionado pelo Ministério da Educação. Tinha como objetivos principais proporcionar a igualdade no acesso ao ensino Superior e diminuir a evasão. Porém, por motivos de baixo retorno de pagamento e problemas político-operacionais, acabou falindo em 1997.

Nesse mesmo ano (1997), o Banco Mundial (BM) apresentou um conjunto de reflexões que apontava certo distanciamento do Estado com o povo, e sugeria que houvesse atitudes para reaproximação entre esses. O Estado tem papel fundamental de criar políticas para Desenvolvimento econômico e Social, e dentro dessas políticas, estavam as de reordenamento da educação superior. Então programas de incentivo foram criados para minimizar a quantidade de vagas ociosas no Ensino Superior, que são explicados nos tópicos seguintes.

\subsection{Financiamento Estudantil (FIES)}

Após o fim do programa de crédito estudantil (1997), o governo federal criou o Fundo de Financiamento do Ensino Superior (FIES) em 1999, na tentativa de que mais estudantes pudessem entrar e se manter, preenchendo as inúmeras vagas ofertadas pela educação privada. O programa de financiamento foi estabelecido em 2001 pela Lei Federal n 10.260.

Como já dito, o Fies é o substituto do CREDUC e a evolução do programa, em número de contratos, pode ser visualizada na Figura 2. 
Figura 2 - Quantidade de bolsas - contratos novos por ano do FIES - Financiamento Estudantil do Ensino Superior - Brasil.

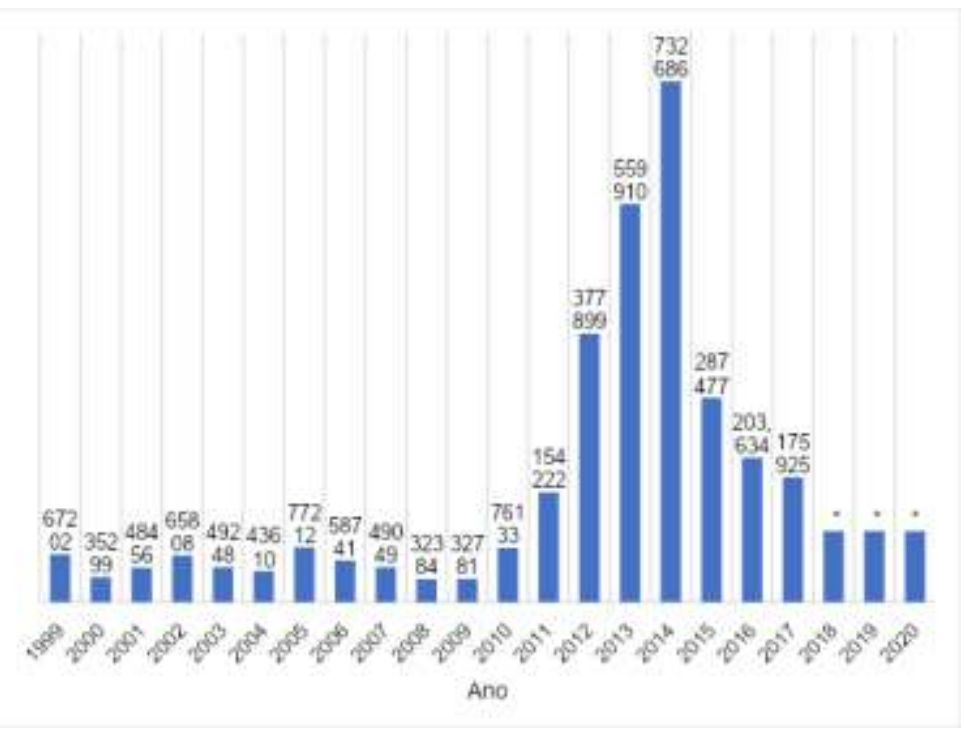

*Valores fornecidos por meio do direito ao acesso. Fonte: Elaboração própria com dados do portal MEC (2020).

O número de vagas ofertadas teve o pico de maior oferta no ano de 2014 e início na expansão em 2010, motivos ao que tudo indica, esse aumento foi em função das mudanças que flexibilizaram o acesso ao programa, onde o Banco Central do Brasil exerceu papel fundamental, colocando em vigor a resolução $n^{\circ} 3.842$, de 10 de março de 2010 . Houveram reduções de taxa efetiva de juros para os contratos que entraram em vigor antes da vigência e os que futuramente seriam efetivados.

Além disso, houve alterações no período de carência que passou a ser de 18 meses, com período de amortização de três vezes o tempo de duração do curso, mais 12 meses. O período de inscrições começou a ser contínuo durante o ano, e os fiadores foram substituídos pelo Fundo de Garantia de Operações de Crédito Educativo (FGEDUC), onerando as despesas da União.

O número de estudantes na rede privada não crescia na mesma proporção que os beneficiados do programa após a reforma, enquanto houve acréscimo no FIES de 31\%, as matrículas representaram apenas 6,6\% se comparado os anos de 2013 e 2014, o que levou a crer que, quem estava ganhando com essas mudanças eram os alunos que já se encontravam nas IES. (Clark et al., 2020).

Em 2014 o país entrou num processo de crise econômica e política, necessitando de reformas. Nesse cenário que o MEC inseriu o pré-requisito de nota do Enem para inscrição no programa FIES, que deveria ser de no mínimo 450 e não ter zerado a redação, restringindo o acesso. Em 2017, com nova reformulação, foi retirado o período de carência e vinculado o pagamento do financiamento à renda do estudante. Essas alterações são possíveis motivos para redução da oferta do programa.

Nas novas regras para se obter o Financiamento, ano de 2020, um dos critérios para obtenção da bolsa é a nota do aluno no Exame Nacional do Ensino Médio (Enem) e não possuir renda superior à três salários mínimos, com uma taxa de juros zero, e o pagamento do financiamento se inicia um mês após a conclusão do curso.

Já no P-Fies, também ocorreu reformulação e nova criação, que teve seu início no segundo semestre de 2020 possuindo características diferentes: é um programa independente do Fies, não tem como critério notas do Enem, o limite de renda é de até cinco salários mínimos e pode ser contratado durante todo o ano. O quadro 2 mostra pontos marcantes em forma de resumo do programa no Brasil. 
Quadro 2 - Fundo de Financiamento Estudantil no Brasil - fies.

\begin{tabular}{|l|l|}
\hline Programa & Fundo de Financiamento do Ensino Superior (FIES) \\
\hline Ano de Criação & 1999 \\
\hline Tipo & Programa de Financiamento \\
\hline Objetivos & $\begin{array}{l}\text { Ensino Superior; } \\
\text { Preencher vagas ofertadas pelo setor privado; }\end{array}$ \\
\hline Informações & $\begin{array}{l}\text { 2010 passou a ser operacionalizado pelo FNDE; } \\
\text { Importantes }\end{array}$ \\
& $\begin{array}{l}\text { 2011 regulamentado pela Lei 12.513; } \\
\text { 2017 Reformulação do programa; } \\
\text { 2020 Criação do P-Fies }\end{array}$ \\
\hline
\end{tabular}

Fonte: Autores (2020).

O programa é vital para que mais pessoas possam ingressar e concluir o Ensino Superior, porém passou por dificuldades de se manter economicamente, principalmente por inadimplência dos já beneficiados por este.

\subsection{Programa Universidade para todos (PROUNI)}

O Programa Universidade para Todos (ProUni) foi criado pelo Governo Federal em 2004 e regulamentada pela Lei 11.096, de 13 de janeiro de 2005. Esse programa oferece bolsas estudantis em instituições de Ensino Superior privadas, podendo ser de 50\% para alunos com renda bruta familiar de até três salários mínimos por pessoa, ou integrais (100\%), para alunos que tenham renda bruta familiar de até 1,5 salários mínimos por pessoa (Miranda \& Azevedo, 2020).

O programa se destina principalmente a estudantes de escolas públicas, atingindo a maior parcela da população carente, mas atende também portadores de deficiência, aos termos da lei, e professores atuantes na rede pública para cursos de Licenciatura e pedagogia (Brasil, 2005).

$\mathrm{O}$ acesso de estudantes às IES privadas com bolsas propicia isenção fiscal por parte da instituição, como dos tributos listados a seguir:

I) Contribuição para o programa de integração social (PIS); II) Contribuição social sobre o lucro líquido (CSLL); III Contribuição social para o financiamento da seguridade social (COFINS) e IV Imposto sobre renda de pessoas jurídicas (IRPJ). (Haas \& Pardo, 2017, p.723)

A isenção ocorre pelo fato de o estudante com bolsa do PROUNI não ressarcir o governo após a conclusão do curso. No ano de 2005, o Prouni distribuiu cerca de 112.275 bolsas no Brasil e em 2020, esse número subiu para 420.317 bolsas, houve então aumento de 274,37 \%. (BRASIL, 2005, 2020). A evolução das bolsas pode ser analisada na Figura 3 que traz a evolução por triênio desde a criação até o ano de 2020. 
Figura 3 - Número de bolsas ofertadas Prouni por triênio.

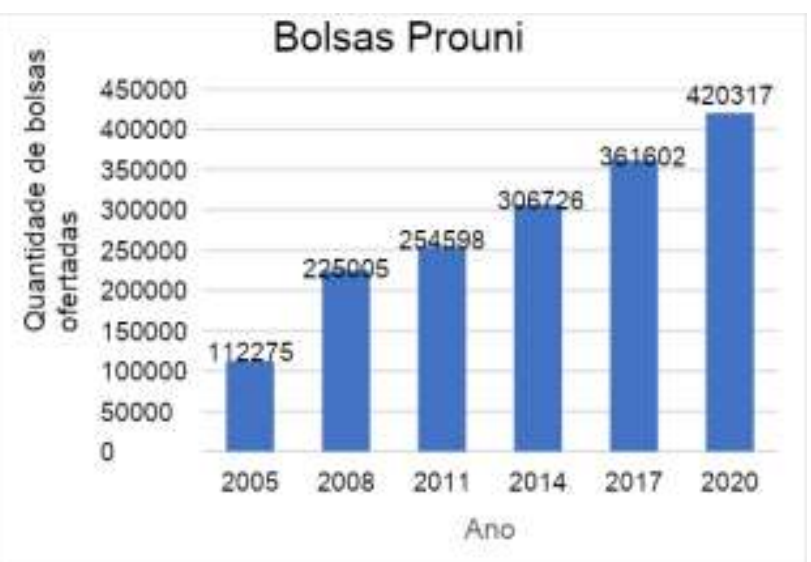

Fonte: Elaboração própria com dados do portal MEC e pelo direito ao acesso de informação (2020).

A permanência do aluno no programa está em função de o bolsista ter aproveitamento mínimo de $75 \%$ nas disciplinas cursadas em cada período, podendo ser encerrada a bolsa caso não alcance essa porcentagem limite.

O Quadro 3 resume informações importantes sobre o PROUNI para melhor entendimento.

Quadro 3 - Programa Universidade para Todos no Brasil- PROUNI.

\begin{tabular}{|l|l|}
\hline Programa & PROUNI \\
\hline Ano de Criação & 2004 \\
\hline Tipo & Programa de Bolsas estudantis \\
\hline Objetivos & $\begin{array}{l}\text { Acesso às IES por bolsa e destinado a Estudantes de escola pública, portadores de deficiência e } \\
\text { professores atuantes na rede publica }\end{array}$ \\
\hline $\begin{array}{l}\text { Informações } \\
\text { Importantes }\end{array}$ & $\begin{array}{l}\text { Criado em 2004, mas regulamentado em 2005; } \\
\text { Propicia isenção fiscal às IES privadas; } \\
\text { O aluno precisa de 75\% de aprovação nas disciplinas cursadas para se manter no programa; } \\
\text { Possui bolsa permanência de 300,00 reais }\end{array}$ \\
\hline
\end{tabular}

Fonte: Autores (2020).

Vale ressaltar que o acadêmico com bolsa integral matriculado em cursos presenciais com duração mínima de seis semestres e a carga horária em média seja igual ou superior a seis horas, terá direito a concorrer uma bolsa permanência de R\$ 300,00. Esse auxílio visa garantir que o aluno consiga permanecer na educação superior, por motivos do programa ser destinado às pessoas de baixa renda, na tentativa de reduzir as evasões durante o curso.

\subsection{Sistema de Seleção Unificada (SISU)}

Novo método de seleção para ingresso no ensino superior de Universidades públicas, criado em 2010 por meio da Portaria Normativa $\mathrm{n}^{\circ}$ 02. Proposto para diminuir a quantidade de exames descentralizados e assim, reduzir gastos, democratizar o acesso e também, por seguir a lei das cotas, é um instrumento de inclusão para grupos sub-representados.

É considerado um mecanismo de maior análise ao aluno, pois já estando de posse de seu desempenho, no Exame Nacional de Ensino Médio, pode se inscrever em mais de uma universidade e ir acompanhando as notas de corte dentro do sistema. Ariovaldo e Nogueira (2018) defendem o seguinte: 
(...) SiSU afeta diretamente o modo como os candidatos escolhem seus cursos. Como já observamos anteriormente, no SiSU, o candidato realiza sua escolha de curso já tendo acesso à sua própria nota, obtida no ENEM do ano anterior além das notas de corte estimadas para cada curso, atualizadas diariamente10. Essas informações permitem estabelecer com maior precisão um ajustamento entre suas escolhas e as opções em que pode realmente ser aprovado. Já no vestibular tradicional, o concorrente tem acesso somente às notas de corte de cada curso nos anos anteriores, assim, a possibilidade de ajustamento das preferências às probabilidades reais de aprovação é mais difícil e se dá com menos exatidão. (Ariovaldo \& Nogueira, 2018, p.160)

O Quadro 4 resume informações necessárias para entendimento de como funciona o sistema.

Quadro 4 - Sistema de Seleção Unificada no Brasil - SISU.

\begin{tabular}{|l|l|}
\hline Programa & Sistema de Seleção Unificada (SISU) \\
\hline $\begin{array}{l}\text { Ano de } \\
\text { Criação }\end{array}$ & 2010 \\
\hline Tipo & Meio de Ingresso em Instituições públicas \\
\hline Objetivos & $\begin{array}{l}\text { Maior Análise de Desempenho para o aluno; diminuir quantidade de exames descentralizados; } \\
\text { Democratizar o acesso por meio de leis de cotas }\end{array}$ \\
\hline $\begin{array}{l}\text { Informações } \\
\text { Importantes }\end{array}$ & $\begin{array}{l}\text { Criado pela portaria Normativa } n^{\circ} 2 ; \\
\text { Aluno consegue acompanhar atualização de notas de corte referentes aos cursos escolhidos; } \\
\text { Utiliza nota do Enem }\end{array}$ \\
\hline
\end{tabular}

Fonte: Autores (2020).

Dessa forma o candidato pode escolher as opções que tenha maiores chances de ser aprovado, afinal ele consegue acompanhar na plataforma online e ajustar e mudar de curso e/ou instituição.

\subsection{Expansão do EAD no Brasil}

Modelo anunciado em 1996 (Quadro 5), no artigo 80 da Lei 9.394 - Lei de Diretrizes e Bases da Educação Nacional, LDBEN, regulamentado pelo decreto de $\mathrm{n}^{\circ} 2.494$ de 1998 , que ficou definido por ser uma forma de ensino que dá a oportunidade ao aluno da auto aprendizagem, através de meios de comunicação. (Brasil, 1998).

O Artigo 80 do decreto 2.494, de 1998, descreve:

Art. 80. O Poder Público incentivará o desenvolvimento e a veiculação de programas de ensino a distância, em todos os níveis e modalidades de ensino, e de educação continuada.

$\S 1^{\circ}$ A educação a distância, organizada com abertura e regime especiais, será oferecida por instituições especificamente credenciadas pela União.

$\S 2^{\circ}$ A União regulamentará os requisitos para a realização de exames e registro de diploma relativos a cursos de educação a distância.

$\S 3^{\circ}$ As normas para produção, controle e avaliação de programas de educação a distância e a autorização para sua implementação, caberão aos respectivos sistemas de ensino, podendo haver cooperação e integração entre os diferentes sistemas. (Regulamento)

$\S 4^{\circ}$ A educação a distância gozará de tratamento diferenciado, que incluirá:

I - Custos de transmissão reduzidos em canais comerciais de radiodifusão sonora e de sons e imagens e em outros meios de comunicação que sejam explorados mediante autorização, concessão ou permissão do poder público;

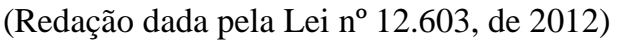

II - Concessão de canais com finalidades exclusivamente educativas;

III - reserva de tempo mínimo, sem ônus para o Poder Público, pelos concessionários de canais comerciais. (Brasil, 1998). 
Quadro 5 - Educação à Distância no Brasil - EAD.

\begin{tabular}{|l|l|}
\hline Programa & Ensino a Distância \\
\hline $\begin{array}{l}\text { Ano do } \\
\text { Marco } \\
\text { Regulatório }\end{array}$ & 1996 pelo Art. 80 LDBEN \\
\hline Tipo & Modalidade de Ensino \\
\hline Objetivos & Possibilitar que atividades educativas sejam desenvolvidas nos mais diversos espaços-tempo \\
\hline $\begin{array}{l}\text { Informações } \\
\text { Importantes }\end{array}$ & $\begin{array}{l}\text { Instituído a fim de expandir o ensino, ultrapassando as barreiras do recorte regional, diversificar a } \\
\text { forma de ensino. }\end{array}$ \\
\hline
\end{tabular}

Fonte: Autores (2020).

O modelo de Ensino a Distância é caracterizado por uma separação Espacial ou temporal entre professor e aluno e são mediados por tecnologias de informação e de comunicação. Como exemplo, a Universidade Aberta do Brasil, criada pelo MEC e regulamentada pelo Decreto $n^{\circ} 5.800$ de 2006, forma a parceria entre níveis governamentais: Federal, Estadual e Municipal. Por ela, inúmeras tecnologias de comunicação têm como objetivo a oferta de cursos superiores na modalidade a distância e por estar interligado com os três níveis de governos, visam a expansão e a interiorização do modelo EaD, para que haja menor desigualdade de ofertas de vagas, principalmente nas regiões interioranas do país.

Na legislação brasileira, os decretos $n^{\circ} 9.057$ e $n^{\circ} 9.235$, ambos de 2017, já possibilitavam duas modalidades de ensino, uma presencial e outra à distância. A primeira permitia até $20 \%$ das atividades com ferramentas de ensino à distância, sendo ampliada para 40\%, em 2020, através da Portaria 2.117/2019. Na segunda (EaD), a relação é de 70\% à distância e 30\% presencial.

De 2000 a 2018 houve acréscimo das matrículas em Universidades, passando de 2.699 .532 a 8.450.755, aumento de 213\%. (Brasil, 2000, 2018), destacando-se o crescimento expressivo da EaD como pode ser visto na Figura 4. Entre 2010 a 2018 houve crescimento dessa modalidade em 121\%, enquanto o presencial teve aumento de 17\%. (Ministério Da Educação, 2020). 
Figura 4 - Quantidade de matrículas nos cursos superiores presencial x EaD - Educação à distância.

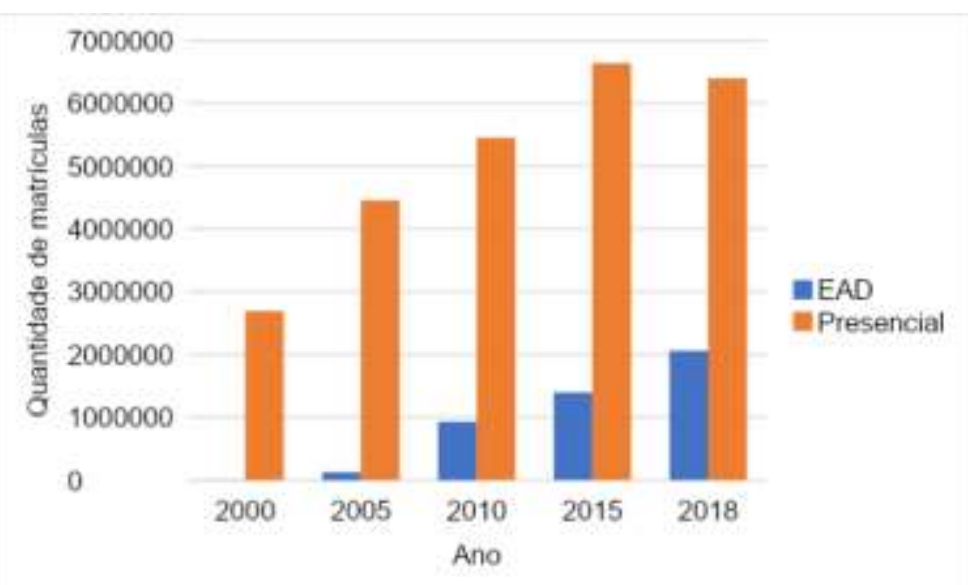

Fonte: Elaboração própria com dados do portal INEP (2019).

$\mathrm{O}$ ensino EaD ainda não superou, em quantidade de matrículas o ensino presencial, porém cresce numa escala expressiva e se coloca como forma alternativa para formação superior.

\section{Educação Superior, Interiorização e Desenvolvimento Regional no Brasil}

Dentro dessa necessidade de expansão e aumento da escolaridade média da população as políticas públicas exercem papel fundamental no processo de interiorização das Instituições de ensino, criar mecanismos de inclusão da população marginalizada e estabelecer programas que possibilitem a entrada e permanência do estudante.

Programas de expansão e interiorização das IES tornou possível que milhares de pessoas pudessem obter diplomas sem precisarem se mudar para cidades maiores, além de atraírem mais estudantes e profissionais, contribuindo para a economia do Município e da região. Mesmo que os envolvidos façam movimentos pendulares, precisam consumir enquanto estão no local de trabalho e de estudo. Por esse motivo, Soares et. al (2010) afirmam que essa influência resulta em desenvolvimento local e regional.

A mudança geográfica da oferta de vagas em universidades provocou diminuição da assimetria que existia de formação e trabalho qualificado, que era um privilégio das capitais. Em 2018, de acordo com o INEP (2019), das 2.537 Instituições de Ensino Superior no Brasil 1.633 se localizam em cidades de interior. Essa alteração pode ser vista no Quadro 6.

Quadro 6 - Número de instituições de Ensino Superior no Brasil, 2000-2018.

\begin{tabular}{|c|c|c|c|c|c|c|c|c|c|}
\hline \multirow{2}{*}{ TIPO } & \multicolumn{3}{|l|}{2000} & \multicolumn{3}{|l|}{2018} & \multicolumn{3}{|c|}{ Variação (\%) } \\
\hline & Capitais & Interior & Total & Capitais & Interior & Total & Capitais & Interior & Total \\
\hline Públi & 59 & 117 & 176 & 98 & 201 & 299 & $66 \%$ & $72 \%$ & $70 \%$ \\
\hline Privada & 376 & 628 & 1.004 & 806 & 1432 & 2238 & $114 \%$ & $128 \%$ & $123 \%$ \\
\hline
\end{tabular}

Fonte: Elaboração própria com dados do censo da educação superior. (INEP, 2019)

Alves e Gumbowsky (2017) nomearam essa interação de: "economia do conhecimento", porque além da informação, cultura e pesquisa, ainda promovem desenvolvimento econômico. Com a maior circulação de recursos financeiros há expansão do consumo e consequentemente, da produção e do crescimento urbano no entorno, pois estudantes tendem a migrarem para morar próximo ao local de estudo, estimulando a atividade produtiva e imobiliária.

Quando essas Instituições se instalam em cidades de pequeno e médio porte, os impactos são sentidos de forma ampliada, por possuírem uma economia mais estática se comparada aos maiores centros urbanos, pois estes últimos já possuem 
mercado para escalas de produção e de demanda.

Considerado o maior incentivo para esse processo de interiorização, foi a criação do REUNI, impulsionando a criação de universidades federais, além da interiorização dessas. Ficou conhecido como o principal marco do processo de expansão dessas Instituições e se embasa em três ciclos principais, que são definidos por Máximo (2020):

O ciclo de reestruturação se caracteriza pela expansão a partir das universidades e campi existentes, com a ampliação de vagas associadas ao incremento da infraestrutura e do quantitativo de docentes. A interiorização decorre quando se inicia a implantação dos novos complexos educacionais, vinculados às universidades existentes ou implantados a partir de novas universidades criadas, que também passaram a contar com alguns campi existentes, mas que foram desmembrados de outras universidades. Nesse mesmo processo, ocorre a integração e a internacionalização, com a implantação de universidades multicampi, alguns inclusive em diferentes Estados, com propostas acadêmicas voltadas à integração regional ou internacional (Máximo, 2020, p.4).

O programa de reestruturação e expansão de Universidades Federais foi criado por meio do decreto de $\mathrm{n}^{\circ} 6.096$ no ano de 2007, instaurado com as principais finalidades de:

Aumentar a quantidade de alunos do sistema superior federal, alterar a relação entre a quantidade de aluno por professor, flexibilizar o uso do EAD e aumentar o índice de conclusão dos cursos de graduação da expansão das universidades nos interiores do país (Mancebo et al., 2015, p. 38).

A descentralização das Universidades possibilitou a oferta de vagas em regiões mais interioranas. Paula (2019, p.67) evidenciou que o programa, nessas cidades de interior, influenciou não somente no âmbito educacional, mas também transformações socioespaciais causadas pelos novos campis como "crescimento do mercado imobiliário, aumento de instalações de restaurantes destinados preferencialmente ao público estudantil, lanchonetes, bares, fotocopiadoras, papelarias, lojas de equipamentos de informática, etc."

Os incentivos e políticas de interiorização fizeram com que houvesse aumento da quantidade de IES principalmente na região Nordeste e em 18 anos (de 2000 a 2018) foram criadas 409 Instituições, porém ficando atrás da região Sudeste que foram criadas 459, esses dados podem ser avaliados na Figura 5. 
Figura 5 - Número de Instituições de Ensino Superior - IES por Região no Brasil.

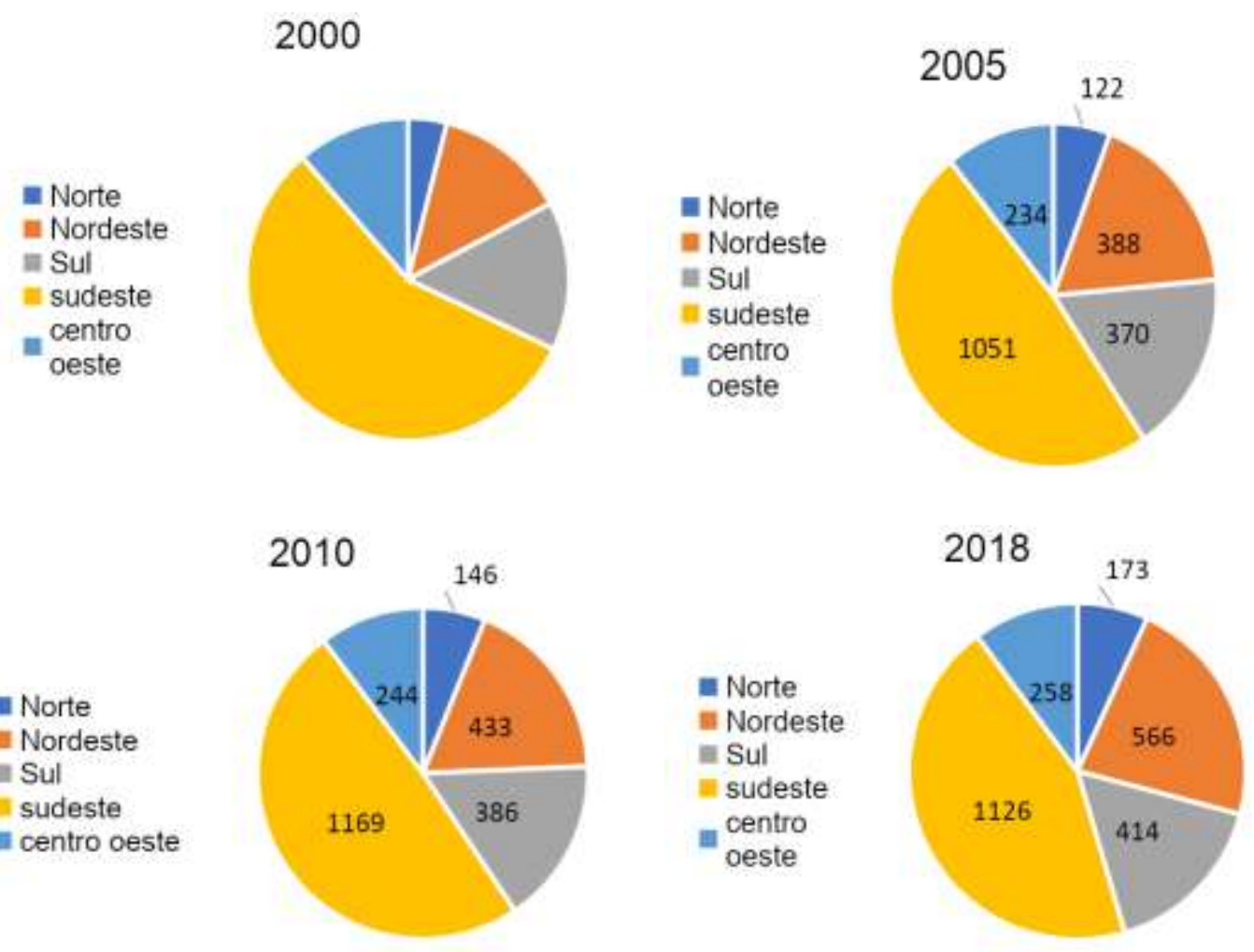

Fonte: Elaboração própria com dados do censo da educação superior. (INEP, 2019).

Outro processo que influencia a interiorização foi a criação dos Institutos Federais (IFs) que simbolizam a abrangência do ensino técnico e tecnológico, por meio do Decreto Federal n ${ }^{\circ} 6.095 / 2007$, onde foram estabelecidas diretrizes para integração de instituições federais deste tipo de formação.

A expansão dos IFs é parte do Plano de Expansão da Rede Federal de Educação Profissional, por meio da Lei no 11.195, de 18 de novembro de 2005, que tem como um dos objetivos, implantar unidades educacionais em periferias dos grandes centros urbanos, municípios interioranos que se encontram distantes das capitais e metrópoles. Essas intervenções possuem critérios que são ligados de forma direta ao desenvolvimento regional (Máximo, 2020).

De acordo com informações do Ministério da Educação (2018), em 2006 havia um total de 144 unidades de instituições federais, e em 2018 esse número subiu para 659 unidades.

Em 2007 foi instaurada a Política Nacional de Desenvolvimento Regional (PNDR), onde foram estabelecidos critérios macrorregionais e sub-regionais, os quais deveriam nortear ações do governo em função do desenvolvimento, com menos disparidades entre as regiões brasileiras. Essa política, contudo, se baseia principalmente em duas variáveis principais: “a) rendimento médio mensal por habitante, englobando todas as fontes declaradas (salários, benefícios, pensões, etc.); e b) taxa geométrica de variação dos produtos internos brutos municipais por habitante." Porém, deveriam estar integradas na análise de desenvolvimento aspectos como: "presença de IES e de Instituições Científicas, Tecnológicas e de Inovação (ICTs), densidade populacional, índice de valor agregado nos setores produtivos locais, presença de empresas e empreendedores" (Centro de Estudos e Debates Estratégicos, 2018, p.26).

Diante disso pode-se entender como Desenvolvimento Regional como sendo uma conjuntura de variáveis, onde uma delas é a distribuição das Instituições de Ensino Superior de forma mais homogênea dentro das regiões brasileiras, com a finalidade de diminuir a disparidade regional.

A relação entre políticas públicas e desenvolvimento regional pode ser entendida como: “[...] a formulação de 
políticas públicas de desenvolvimento regional impõe a consideração de diferentes perspectivas temáticas - educação, ciência, tecnologia e inovação, meio ambiente, empreendedorismo, infraestrutura, tributação, agricultura, entre outros [...]" (Centro de Estudos e Debates Estratégicos, 2018, p.51).

A expansão do Ensino Superior abrange mais de uma perspectiva temática dos eixos do desenvolvimento regional: a) educação, ciência principalmente dentro do campo de pesquisa, inovação e tecnologia dentro do meio acadêmico e em conjunto com empresas.

Diante das intervenções do Estado e dos programas estudados, os resultados analisados demonstram que realmente houve expansão do Ensino Superior, porém ainda não é o ideal, isso pode ser observado pelos índices de comparação ao que deveriam ser atendidos, de acordo com o PNE, em cada ano. No site do Programa Nacional de Educação em Movimento (2020) verifica-se que o objetivo do país é chegar à taxa bruta de matrículas no Ensino Superior em $50 \%$ e este se encontra em $30,3 \%$. Enquanto a taxa líquida de escolarização tem como meta 33\% e se encontra em 20,2\%. O Quadro 7 resume o programa de Reestruturação.

Quadro 7 - Resumo do Plano de Reestruturação e Expansão das Universidades Federais no Brasil - Reuni.

\begin{tabular}{|l|l|}
\hline Programa & Planos de Reestruturação e Expansão das Universidades Federais (Reuni) \\
\hline Ano de Criação & 2007 \\
\hline Tipo & Programa de Reestruturação de IES Federais \\
\hline Objetivos & $\begin{array}{l}\text { processo de interiorização das Instituições de ensino; } \\
\text { Possibilitar que pessoas obtivessem acesso ao Ensino Superior sem a necessidade de } \\
\text { morar em grandes cidades; } \\
\text { Mudança Geográfica de oferta de vagas para Educação Superior. }\end{array}$ \\
\hline Informações Importantes & $\begin{array}{l}\text { Provocou diminuição da assimetria que existia de formação e trabalho qualificado; } \\
\text { Em 2018 cerca de 1.633 IES se localizavam em cidades de interiores; } \\
\text { Impulsionou a criação de universidades federais além da interiorização dessas. }\end{array}$ \\
\hline
\end{tabular}

Fonte: Autores (2020).

Todos os programas já mencionados contribuíram para o processo de expansão do ensino superior, no último censo de 2019 indica que no país existem 2.608 Instituições de Ensino Superior (IES), em 2009 haviam 2.314, ou seja, um crescimento de 12,71\% em 10 anos. (Instituto Nacional de Estudos e Pesquisas Educacionais, 2020).

Ademais, além de todos estes aspectos, conforme Silva et al. (2021) é indiscutível a necessidade em desenvolver metodologias de ensino que sejam, de fato, eficientes para a construção do saber. Desta forma, aliando estratégias de interiorização da educação superior com práticas de aprendizagem eficientes, o Brasil poderá ter sucesso na educação.

\section{Considerações Finais}

Através da linha cronológica na história da educação superior no Brasil verificou-se que as IES demoraram a ser implantadas, desenvolveram e ainda estão em processo de expansão. A expansão dessas IES pôde contribuir para o maior acesso à educação, por estarem distribuídas em todas as regiões, proporcionando maior facilidade para ingresso dos estudantes que estavam na periferia do país, e isso se torna mais evidente quando se trata das instituições em locais interioranos.

Quanto às políticas públicas fica evidente a necessidade de interferência do Estado para que se amplie a oferta do Ensino Superior e que esse consiga ser acessível e chegue a todas as classes sociais e em todas as localidades no Brasil.

Constatou-se que políticas públicas de educação afetam não somente o campo de atuação principal, mas também outros âmbitos, como o que pôde ser observado na pesquisa que investimento em expansão da educação superior contribui com 
o desenvolvimento regional e local onde as IES estão localizadas, por essas instituições serem agentes propulsores da sociedade, da economia, da cultura e da educação.

A própria expansão do ensino é um mecanismo de análise de desenvolvimento. As IES contribuem de forma direta com os três pilares do desenvolvimento: economia, social, e cultural, sendo assim a educação superior e as instituições são de suma importância para o foco das políticas públicas.

Vale ressaltar que o Plano Nacional de Educação - PNE determina diretrizes, metas e estratégias para a política educacional no período de 2014 a 2024, sendo assim, necessário acompanhamento a fim de avaliar a evolução dentro dos objetivos estabelecidos, podendo então ser tema de pesquisas e análises futuras.

\section{Referências}

Alves, J. A. B \& Gumbowsky, A. (2017). Impactos econômicos da Universidade do Contestado (UnC) no desenvolvimento do município de Canoinhas, SC. Interações. 18(4), 55-68,

Aprile, M. R \& Barone, R. E. M. (2009). Educação superior: políticas públicas para inclusão social. @ mbienteeducação, 2(1), 39-55.

Ariovaldo, T. C.C \& Nogueira C. M. M. (2018). Nova forma de acesso ao ensino superior público: um estado do conhecimento sobre o sistema de seleção unificada - SiSU. Revista Internacional de Educação Superior. 4(1), 152-174.

Brasil. Ministério da Educação e Cultura. (1998). Decreto $n^{\circ} 2.494$, de 10 de fevereiro de 1998. MEC

Brasil, Ministério da Educação (2019). Banco de dados Programa Universidade para Todos 2005-2019. MEC

Brasil, Ministério da Educação (2017). Resumo Técnico Censo da Educação Superior de 2000 a 2017. MEC

Brasil. (2014). Lei n.13.005, de 25 de junho de 2014. Aprova o Plano Nacional de Educação - PNE e dá outras providências. Diário Oficial da União, Brasília, DF.

Castells, M. (2003) A cidade na nova economia. Tradução de Jorge Alberto Machado. In: Machado, J. A. S. (2003) Trabalho, economia e tecnologia: novas perspectivas para a sociedade global. 2. ed. São Paulo: Tendenz, Bauru: Praxis, Parte 1, cap. 1, 15-29.

Clark, G., Nascimento, S. P. D \& Moura Junior, C. A. D. S. (2020) O financiamento estudantil no ensino superior privado: uma análise do fundo de financiamento estudantil (FIES) sob a ótica do direito econômico. Arquivo Jurídico, 7(1), 196-213.

Dallabrida, V. R. (2010). Desenvolvimento e governança territorial: um ensaio preliminar sobre a necessidade da regulação no processo de gestão do desenvolvimento. Redes. 15(3), 165-186.

Durham, E. R. (2010). A política educacional do governo Fernando Henrique Cardoso: uma visão comparada. Novos Estudos, 1(88), $153-179$.

Guedes, L. G. D. R \& Santos, F. D. F. (2019). Transferência de conhecimento e tecnologia entre empresa/universidade: estudo de caso na fundação de amparo à pesquisa do estado de Goiás. Revista de Desenvolvimento Econômico, 2(43), 344-362.

Haas, C. M \& Pardo, R. D. S. (2017). Programa Universidade para Todos (PROUNI): Efeitos financeiros em uma instituição de educação superior privada. Avaliação: Revista da Avaliação da Educação Superior, 22(3), 718-740.

Instituto nacional de estudos e pesquisas educacionais - INEP (2019). Sinopse estatística da educação superior - 2000 a 2019. INEP

Lima, K. R. d. S. (2011) O Banco Mundial e a educação superior brasileira na primeira década do novo século. Katálysis, 14(1), 86-94.

Mancebo, D., Vale, A. A. D \& Martins, T. B. (2015). Políticas de expansão da educação superior no Brasil 1995-2010. Revista Brasileira de Educação, $20(60), 31-50$.

Máximo, R. (2020) Efeitos territoriais de políticas educacionais: a recente expansão e interiorização do ensino federal em cidades não metropolitanas no Ceará. URBE, 12(1), 1-17.

Mendonça, A. W. P. A (2000). Universidade no Brasil. Revista Brasileira de Educação, 2(14), 131-194.

Miranda, P. R. \& Azevedo, M. L. N. D. (2020). Fies e Prouni na expansão da educação superior brasileira: políticas de democratização do acesso e/ou de promoção do setor privado-mercantil? Educação \& Formação, 5(3), 315-333.

Ministério da Educação (2020). Dados da Educação superior - Quantidade de Contratos FIES. MEC

Ministério da educação (2018). Expansão da Rede Federal. MEC

Paula, K. A. (2019). O processo de verticalização na zona central da cidade de Viçosa-MG: uma análise a partir da expansão da Universidade Federal de Viçosa e do seu impacto na estruturação do espaço urbano. GeoTextos, 15(1), 65-87.

Plano nacional de educação em movimento (2014). Base legal. MEC. 
Research, Society and Development, v. 10, n. 10, e207101018759, 2021

(CC BY 4.0) | ISSN 2525-3409 | DOI: http://dx.doi.org/10.33448/rsd-v10i10.18759

Sguissardi, V. (2008). Modelo de expansão da educação superior no Brasil: predomínio privado mercantil e desafios para a regulação e a formação universitária. Educação \& Sociedade, 29(105), 991-1022.

Serra, M., Rolim, C., \& Bastos, A. P. (2020). Universidades e desenvolvimento regional-as bases para a inovação competitiva. Rev. Bras. Inov, 19(e0200017), $1-4$.

Silva, C. L, Lopes, C \& Junior, W. M. (2009). Intervenção do Estado e desenvolvimento local: uma análise cross section dos municípios paranaenses. Interações, 10(1), 41-53.

Silva. R. A. R. et al. (2021). A Aprendizagem Cooperativacomo metodologia ativa no Ensino Médio: Percepção de alunos de uma escola pública da Cidade de Milagres, Ceará. Research, Society and Development, 10(8) e17410817166.

Silveira, D. T.\& Córdova, F. P. A pesquisa científica. In: Gerhardt, T. E, \& Silveira, D. T. (2009). Métodos de pesquisa. UFRGS, 31-44.

Soares, B. R., Ramires, J. C., Oliveira, H. D., Melo, N. D., Souza, M. D., \& Ribeiro Filho, V. (2010). Uberlândia (MG): leituras geográficas de uma cidade média em transição. Agentes econômicos e reestruturação urbana e regional: Tandil e Uberlândia. São Paulo: Expressão Popular, 157-285

Theis, I. M. (2019). O que é desenvolvimento regional? Uma aproximação a partir da realidade brasileira. Redes, 24(3), 334-360.

Vieira, S. (1991) O discurso sobre a universidade nos anos 80. Cadernos CEDES, 25, 75-87.

Villalta, L. C. (1997). O que se fala e o que se lê: língua, instrução e leitura In: Novais, F. A. \& Melo E Sousa, L. de. História da vida privada no Brasil: cotidiano e vida privada na América portuguesa. São Paulo: Companhia das Letras, 1, 331-385.

Viegas, E. R. D. S, Santana, C. F. P. Á \& Noda, C. M. C. (2020). O conceito de política pública e suas ramificações: alguns apontamentos. Brazilian Journal of Development, 6(7), 43415-43425. 